\title{
Docência no ambiente virtual durante a Covid-19: análise de um percurso de formação de professores do ensino superior
}

\section{Teaching in the virtual environment during Covid-19: analysis of a teacher training at higher education}

\author{
${ }^{1}$ Viviane Ines Weschenfelder vweschenfelder@unisinos.br \\ ${ }^{1}$ Adriane Brill Thum \\ ${ }^{2}$ Caroline Medeiros Martins de Almeida
}

\section{RESUMO}

Este artigo tem como objetivo analisar o percurso de formação de professores universitários desenvolvido durante a migração das aulas presenciais para o ambiente virtual, devido a pandemia causada pela COVID-19. A base teórica desta análise é composta por referenciais sobre a formação de professores, educação online e a docência contemporânea. A metodologia escolhida para o texto é o relato de experiência A partir desse relato, é possível identificar um processo de (trans)formação no modo de ser professor(a), oportunizado pela experiência docente no ambiente virtual em conjunto com a formação continuada, tanto no que se refere ao viés pedagógico quanto tecnológico. A qualidade da formação docente desenvolvida deve-se à concepção de formação que ampara as ações da universidade e o engajamento do corpo docente, tornando possível o desenvolvimento de um ethos de formação.

Palavras-chaves: Formação de professores. Ensino superior. Ensino Remoto de Emergência. COVID-19.

\begin{abstract}
This article aims to analyze the path of teacher training developed with faculty during the migration of face-to-face classes to the virtual environment, due to the pandemic caused by COVID-19. The theoretical approach of this analysis is composed of references for teacher education, online education, and contemporary teaching. The methodology chosen for the text is the experience report. Based on this report, it is possible to identify a process of transformation in teaching. These transformative practices were possible considering both teaching experience in the virtual environment and teacher training, organized with pedagogical and technological tools. The quality of teacher training developed is due to the concept of teacher education that supports the actions of the university and the engagement of the faculty, making it possible to develop an educational ethos.
\end{abstract}

Keywords: Teacher training. Higher Education. Emergency Remote Teaching. COVID-19.

1 Universidade do Vale do Rio dos Sinos.

2 Programa de Pós-Graduação em Gestão Educacional da Universidade do Vale do Rio dos Sinos. 


\section{DISTANCIAMENTO SOCIAL CAUSADO PELA COVID-19 E A UNIVERSIDADE: INTRODUÇÃO}

A pedagogia, portanto, é o oposto do isolamento. Suas ferramentas são baseadas no encontro entre educadores e alunos em um ambiente escolar que transforma esse vínculo em um fato único e intransferível. Um encontro articulado em torno do conhecimento. Uma profunda experiência no intelectual, no emocional e no corpo. (NARODOWSKI, 2020, s/p). ${ }^{3}$

Iniciamos este texto com o excerto de Narodowski (2020) no intuito de dimensionar o desafio que foi imposto ao cenário da educação mundial neste primeiro semestre de 2020. A rápida disseminação do Coronavírus (COVID-19), que teve seu início na China em dezembro de 2019, fez com que a Organização Mundial da Saúde (OMS) declarasse situação de emergência internacional e orientasse para o imediato distanciamento social. Com o perigo eminente de difusão e infecção pelo vírus, escolas e universidades foram obrigadas a pararem suas atividades presenciais. Se a pedagogia é o oposto do isolamento (NARODOWSKI, 2020), como podemos pensar a continuidade do encontro com o outro, do ensinar e do aprender, neste contexto desafiador?

Este texto tem como objetivo analisar o percurso de formação de professores universitários desenvolvido durante a migração das aulas presenciais para o ambiente virtual, devido a pandemia causada pela COVID-19.

O percurso foi protagonizado por três segmentos de uma universidade comunitária localizada na região Sul do Brasil: a Formação Docente, que integra o Núcleo de Inovação, Avaliação e Formação (NIAF); a Tecnologia Educacional (TE), setor da Tecnologia da Informação (TI-ASAV) e as Unidades Acadêmicas ${ }^{4}$. Embora a instituição já tivesse mais de dez anos de atuação em educação à distância, o cenário que se apresentou foi totalmente novo, como para a maioria das Instituições de Ensino Superior (IES).

Para este artigo, apresentamos um relato de experiência das primeiras semanas de migração das atividades presenciais para o modo remoto, analisando este processo com o auxílio de autores do campo de formação de professores, da educação online e de estudos sobre docência contemporânea. Embora diversas universidades tenham optado pela suspensão temporárias das aulas, a universidade em questão, assim como outras IES comunitárias, decidiram pela manutenção das atividades, realizando a migração das aulas presenciais para o ambiente virtual $^{5}$. Além de uma adaptação rápida do sistema tecnológico, foi necessário um investimento considerável em atividades de formação docente para que os professores pudessem adequar seus planos de ensino e as aulas no ambiente virtual. É sobre esse investimento, que transformou-se em um processo de formação continuada, que esse artigo se dedica.

Na sequência desta introdução, o artigo está estruturado em cinco partes. Na próxima seção, apresentamos as bases teóricas que dão sustentação para a análise da experiência aqui relatada. Além do entendimento sobre formação de professores universitários (CUNHA, 2010), docência no Ensino Superior (PIMENTA; ANASTASIOU, 2014; ZABALZA, 2011) e Educação Online (MOREIRA; SCHLEMMER, 2020), compartilhamos os princípios que orientam as atividades formativas realizadas. Na seção 3, descrevemos brevemente a metodologia deste artigo, que é o relato da experiência. Em seguida, na seção 4, descrevemos a experiência que é foco deste artigo, ou seja, o conjunto de atividades de capacitação desenvolvidas nas cinco primeiras semanas de migração

3 Texto intitulado “Onze teses urgentes para a pedagogia do contra-isolamento”, disponível em: https://pensaraeducacao.com.br/blogpensaraeducacao/onze-teses-urgentes-para-uma-pedagogia-do-contra-isolamento/. Acesso em: 05 jun. 2020.

4 A universidade é atualmente é composta por três Unidades Acadêmicas: Unidade Acadêmica de Graduação (UAGRAD); Unidade Acadêmica de Pesquisa e Pós-Graduação (UAPPG) e Unidade Acadêmica de Educação Online (UAEO).

5 Mais informações sobre o posicionamento das diferentes universidades do Sul do Brasil podem ser conferidas em: https://g1.globo.com/rs/rio-grande-do-sul/noticia/2020/03/13/universidades-cancelam-atividades-e-escolas-do-rs-alteram-rotinas-devido-ao-coronavirus.ghtml. Acesso em: 05 jun. 2020. 
das aulas para o ambiente virtual. Nesta seção, trazemos alguns dados que dão materialidade para a compreensão deste empreendimento formativo, que articulou saberes pedagógicos e tecnológicos.

Na seção 5, desenvolvemos uma análise da experiência, apontando, com o auxílio dos autores, as potencialidades e os desafios que ainda se apresentam para a qualificação da formação com os professores universitários. Por fim, nas considerações finais, mostramos que a formação docente desenvolvida durante a COVID-19 nos sinaliza para o desenvolvimento de um ethos de formação (DAL'IGNA; FABRIS, 2015), um modo de ser e de agir docente em colaboração com o outro.

\section{REFERENCIAL TEÓRICO}

No Brasil, a Lei n. 13.979, de 6 de fevereiro de 2020, referida como “lei de quarentena”, fala sobre as medidas que podem ser adotadas para o enfrentamento da emergência de saúde pública decorrente do Coronavírus (BRASIL, 2020). A necessidade de isolamento social em função da pandemia fez com que as aulas presenciais do primeiro semestre de 2020 fossem suspensas nas universidades brasileiras. O Art. 207 da Constituição Federal dispõe que: "As universidades gozam de autonomia didático-científica, administrativa e de gestão financeira e patrimonial e obedecerão ao princípio da indissociabilidade entre ensino, pesquisa e extensão”. (BRASIL, 1988). Essa autonomia possibilitou às Instituições de Ensino Superior (IES) basicamente dois caminhos: a interrupção temporária das atividades presenciais ou a migração destas atividades para o ambiente virtual.

Com a opção pela continuidade imediata das aulas de forma remota, foi necessário pensar um trabalho não só de apoio aos docentes, mas de formação continuada, envolvendo as dimensões pedagógicas e tecnológicas. Como planejar um percurso efetivo de formação continuada para professores universitários com a agilidade necessária, visando a migração das aulas presenciais para o ambiente virtual? Quais as bases teóricas que sustentaram essas ações formativas? Nesta seção, nos dedicamos a apresentar brevemente alguns conceitos importantes para a realização deste processo.

Concordamos com Cunha (2010) de que a docência é uma ação complexa que envolve a conjugação de saberes e competências. No Ensino Superior (ES), a docência se constitui na articulação entre os conhecimentos profissionais e os conhecimentos pedagógicos. Em um contexto de crise e imediata transformação do modo de trabalho, a docência tornou-se um empreendimento ainda mais desafiador. Daniel (2020) relata que a pandemia do COVID-19 é um enorme desafio para os sistemas educacionais, principalmente quando se trata de ensino e aprendizagem remotos.

No que diz respeito à formação do professor universitário, Primon e Arroio (2016) comentam a necessidade de formação específica para a sua atuação. Quando falamos de IES, autores apontam uma necessidade iminente de uma reforma educacional nas proposta pedagógicas, nos métodos de avaliação, na estrutura organizacional e principalmente quanto a profissionalização do professor. (PIMENTA; ANASTASIOU, 2014; VIDAL, NETO, 2016). O docente se constitui como um agente capaz de atuar no processo de ensino e de aprendizagem de forma crítica e comprometida. Esta agência está no reconhecimento da potencialidade do aluno e na articulação entre os saberes, gerando uma comunicação efetiva, compartilhamento de conhecimentos e crescimento coletivo (LÉVY, 1999).

Zabalza (2011) afirma que um professor universitário qualificado requer uma formação específica e especializada. Vieira (2014) explica que essa formação possibilita a construção de conhecimentos pedagógicos que contribuam para a qualidade da Educação Superior. Para que ocorra uma formação docente de médio prazo, é imprescindível um plano institucional de formação para a docência universitária. (VIEIRA, 2014). Fica evidente, deste modo, que a formação docente deve ser considerada estratégica pela IES, tendo um setor responsável e com recursos humanos e operacionais para a realização das ações de formação continuada. Segundo Mendes, 
O processo de reflexão contínua e permanente do professor é uma forma de avaliar o próprio trabalho desenvolvido na sala de aula, a fim de perceber as implicações da prática pedagógica na sua formação, assim como perceber a importância dessa prática na vida dos alunos. Desse modo, uma reflexão na e sobre a prática docente contribuirá para o redirecionamento do fazer pedagógico em busca do aperfeiçoamento da ação docente. A ação-reflexão-ação permite perceber, entre outras coisas, se o trabalho desenvolvido dentro e fora da sala de aula está atendendo as expectativas dos alunos, seus interesses e os propósitos da disciplina. (MENDES, 2007, p. 111).

Se a formação de professores no ES é uma tarefa importante e permanente, no contexto da pandemia essa necessidade adquiriu caráter de urgência. A transposição das aulas presenciais para o formato virtual é um empreendimento que exige domínio pedagógico e tecnológico. Mais do que isso, envolve uma profunda reflexão sobre as competências a serem desenvolvidas por cada atividade acadêmica e a condução dos processos de ensino e aprendizagem. Uma reflexão que não teve tempo de ser realizada com profundidade, nem pela equipe que conduziu o processo, nem pelos professores que vivenciaram a experiência da migração. Por essa razão, entendemos que a tomada de decisões ocorreu a partir de princípios que constituem o ethos da universidade, um modo de ser e de agir que caracterizam e atribuem sentido à cultura da instituição e a docência por ela acionada. (DAL'IGNA; FABRIS, 2015).

Um elemento importante neste processo é a entendimento do que vamos chamar de Docência Remota de Emergência. De acordo com Hodges et al (2020, s/p):

É uma mudança temporária da entrega de instruções para um modo de entrega alternativo devido a circunstâncias de crise. Envolve o uso de soluções de ensino totalmente remotas para instrução ou educação que, de outra forma, seriam ministradas presencialmente ou como cursos combinados ou híbridos e que retornarão a esse formato assim que a crise ou emergência tiver diminuído. O objetivo principal nessas circunstâncias não é recriar um ecossistema educacional robusto, mas fornecer acesso temporário a instruções e apoio instrucional de uma maneira que seja rápida de configurar e esteja disponível de maneira confiável durante uma emergência ou crise [tradução nossa].

Argumentamos que este termo seria mais adequado porque estamos tratando de uma tradução de Emergency Remote Teaching, em que o termo teaching em Inglês recebe uma dimensão mais completa que sua tradução comumente utilizada, o termo ensino. Fabris e Dal'Igna (2017, p. 57) definem a docência como "uma condição exercida pelo professor, comprometido com o processo de ensino e com as possíveis aprendizagens promovidas a partir dele”. Exercer a docência não significa apenas transmitir conhecimento, mas conduzir os processos pedagógicos com sujeitos em posição de alunos, com o objetivo de produzir aprendizagens, desenvolver competências. Embora seja uma medida emergencial, distante de algumas condições que historicamente julgamos ideais para a aprendizagem efetiva, os professores não deixaram de se encontrar com os alunos, de conhecer ferramentas tecnológicas que proporcionassem a realização de exercícios e a interação entre os participantes, não deixaram de ser presença educativa.

Com esta reflexão, não queremos traduzir o ensino apenas como transmissão do conhecimento, mas a linguagem da aprendizagem (BIESTA, 2013) tem nos direcionado a pensar que, quando falamos em ensino, estamos desconsiderando as aprendizagens, enquanto o contrário não ocorre. Segundo Biesta (2013, p. 32), “uma das mudanças mais notáveis que ocorreram na teoria e prática da educação nas últimas décadas foi a ascensão do conceito de "aprendizagem” e o subsequente declínio do conceito de "educação” [ensino]". Além disso, autores que trabalham com a educação online têm apontado críticas importantes ao ensino remoto, especialmente quando ele é nomeado como Educação a Distância ou educação online. Moreira e Schlemmer (2020, p. 9), assim caracterizam o ensino remoto desenvolvido durante a pandemia: 
O processo é centrado no conteúdo, que é ministrado pelo mesmo professor da aula presencial física. [...] A comunicação é predominantemente bidirecional, do tipo um para muitos, no qual o professor protagoniza vídeo-aula ou realiza uma aula expositiva por meio de sistemas de webconferência. [...] No ensino remoto ou aula remota o foco está nas informações e nas formas de transmissão dessas informações. A lógica que predomina é a do controle, tudo o que é concebido e disponibilizado é registrado, gravado e pode ser acessado e revisto posteriormente.

Pensar a Docência Remota de Emergência significa assumir o caráter transitório do exercício docente mediado pela tecnologia, que apesar do distanciamento social mantem o compromisso com a aprendizagem dos estudantes e com sua contínua (trans)formação. Significa, também, que vivemos um processo de transformação profunda em nossa docência, e que nunca mais seremos os mesmos após a COVID-19. Por fim, significa que muitos de nós talvez ainda estejamos próximos do ensino transmissivo e de práticas de vigilância, mas que aos poucos seremos tomados pelas aprendizagens construídas e também poderão perceber-se a partir de outras experiências. Não nos cabe julgar, mas tomar o momento de crise como um espaço produtivo de aprendizagem e experimentação, como mostra Tomazinho (2020), porque sabemos em qual direção queremos caminhar.

Segundo Martins e Kersch (2020), mesmo que muitos ainda não tenham se dado conta, as Tecnologias Digitais (TD) têm influenciado muito a forma como as pessoas vivem, imbuindo cada vez mais novos letramentos aos professores para que sejam mediadores no processo de construção do conhecimento. Schlemmer e Moreira (2019) explicam que pela apropriação das TD, as relações culturais, sociais e pedagógicas contemporâneas têm sofrido grandes alterações, rompendo hábitos e comportamentos até então considerados inabaláveis. Para os autores, por estarem presentes nas diferentes esferas da vida das pessoas as tecnologias assumem um papel importante na complexidade dos processos de aprendizagem, quer sejam presenciais ou analógicos, quer sejam digitais ou virtuais. Deste modo, não se trata mais de "classificar e polarizar as gerações ou as culturas em analógica ou digital e, as modalidades educacionais em presencial física ou online", pois as aprendizagens ocorrem "numa perspectiva transcultural, reticular, conectiva e atópica” (SCHLEMMER; MOREIRA, 2019, p. 691).

Bairral e Silva (2018) comentam que não é preciso mais estar presente fisicamente, em determinada hora e dia, para interagir, pois plataformas possibilitam a interação síncrona e assíncrona por diversas mídias como videoconferências, chats, fóruns de discussão etc. Santos e Weber (2013, p. 6) relatam que "a educação online se traduz por toda experiência educacional formal que lança mão do digital em rede, sendo utilizada tanto para experiências presenciais, quanto para semipresenciais ou online, no meio corporativo, acadêmico ou informal”. Estamos assim, caminhando a passos largos em direção a uma transformação digital, que está mudando não apenas nossa docência, mas nossa própria constituição como sujeitos em sociedade. O distanciamento social e a migração das aulas presenciais para o ambiente virtual aceleraram o processo, são estes conceitos apresentamos nesta seção que dão base ao nosso processo formativo, à construção de uma docência remota de emergência.

\section{METODOLOGIA}

Este artigo apresenta um relato de experiência, que Cavalcante e Lima (2012, p. 96) referem como "uma ferramenta da pesquisa descritiva que apresenta uma reflexão sobre uma ação ou um conjunto de ações que abordam uma situação vivenciada no âmbito profissional de interesse da comunidade científica”.

A experiência foi desenvolvida em uma universidade privada do Sul do Brasil e os sujeitos envolvidos são os professores universitários. O corpo docente da IES é composto atualmente por cerca de 850 professores. A migração das aulas presenciais para o ambiente virtual afetou mais de 70 cursos de graduação e 26 programas de pós-graduação. A universidade mantém e desenvolve parcerias estratégicas com empresas e universidades do Brasil e do mundo, que fortalecem a pesquisa e permitem o intercâmbio científico de alunos e pesquisadores. 
A pandemia transformou a sala de aula presencial para virtual remota em 48 horas, o que tornou necessária a realização de diversos encontros de capacitação docente. O presente estudo consistiu em criar momentos de formação continuada sobre os aspectos pedagógicos e tecnológicos relacionados à migração das aulas presenciais para aulas no ambiente virtual, bem como um repositório com materiais para dar suporte aos professores. Este relato de experiência apresenta as ações realizadas durante as primeiras semanas de docência remota de emergência. As atividades com o corpo docente foram todas online, em sua maioria de forma síncrona.

As informações foram coletadas e registradas através de um diário, com anotações pertinentes ao trabalho realizado. Os registros incluíram o tema das formações, os professores ministrantes, número de docentes que acompanhavam as formações e questões que surgiam no decorrer dos encontros. Também consta nesta coleta o material da apresentação das ações realizadas pela equipe de formação docente para a alta administração da universidade. Vale registrar que as autoras deste texto vivenciaram o processo de migração não apenas como professoras, mas como integrantes da equipe de formação, que integra o Núcleo de Inovação, Avaliação e Formação (NIAF) da universidade.

FORMAÇÃO DE PROFESSORES DURANTE A COVID-19: RELATO DE EXPERIÊNCIA

A universidade optou pela migração das aulas presenciais para o ambiente virtual devido a pandemia causada pela COVID-19. O anúncio ocorreu no dia 16 de março de 2020, tendo as aulas interrompidas no mesmo dia. A partir de 18 de março, as atividades presenciais passaram a ocorrer no formato virtual. Para isso, foram criadas mais de três mil novas comunidades no Moodle, que de suporte ao ensino presencial passou a ser o principal meio de registro e comunicação das atividades acadêmicas. Obviamente, este movimento envolveu o trabalho de muitas equipes e a decisão impactou fortemente os estudantes. Muitos(as) alunos(as) não viam-se preparados para dar conta das atividades acadêmicas de forma virtual, tanto no que refere-se à sua organização para estudar à distância, quanto à estrutura necessária para tal, como computador e acesso à internet. Embora a atenção às condições dos alunos tenha sido um trabalho essencial, neste texto focaremos no processo de formação realizado junto aos professores.

As ações de apoio e formação iniciaram logo após o anúncio do distanciamento social. No processo de migração das aulas presenciais para o ambiente virtual, a universidade contou com o apoio das Unidades Acadêmicas (especialmente de Graduação e de Pesquisa e Pós-graduação), da Tecnologia Educacional (TE) e da Formação Docente (NIAF). Vale destacar a importância do comitê organizado pela instituição para pensar ações frente à pandemia, pois algumas ações relacionadas à migração puderam ser planejadas com alguma antecedência, especialmente diante dos cenários que se apresentavam em diferentes países.

Ao trabalharem de forma colaborativa, essas equipes escolheram conjuntamente os temas abordados nas capacitações, os professores que ministraram as formações e as metodologias adotadas nos encontros. Nóvoa (2002) destaca que é importante adotar uma prática de formação que tenha como princípio uma concepção coletiva e de compartilhamento dos conhecimentos, pois o professor tem uma profissão que ainda é autônoma na produção dos seus saberes e tende a ser individualizada, até mesmo solitária em alguns momentos. Por isso, desde o início o sentimento de colegiado do corpo docente da universidade procurou ser fortalecido. Esse sentimento já era fomentado nos eventos das capacitações semestrais, mas com o distanciamento social tornou-se latente pela experiência coletiva e pela necessidade de troca constante entre os pares.

Para realizar a migração das aulas presenciais para o formato digital, desde o início foram considerados elementos como: os significados da presença do professor, as formas de interação, o engajamento dos alunos, produção de materiais e direcionamento nas comunidades de cada disciplina. Em relação aos momentos de formação com os professores, alguns princípios que deram sustentação ao planejamento das atividades foram: articulação entre pedagógico e tecnológico, aprendizagem e compartilhamento entre pares, recorrência de temas 
importantes e disponibilização das gravações e dos tutoriais produzidos, valorização da comunicação entre os professores e senso de pertencimento ao colegiado maior, que é o corpo docente da universidade.

É importante destacar que o anúncio da migração das aulas para o ambiente virtual foi realizado com um plano de ação para apoiar os docentes, conforme relatamos a seguir. A equipe de TE criou um repositório para disponibilizar o conjunto de orientações, tutoriais das ferramentas tecnológicas e gravações das capacitações. Assim, caso os professores não pudessem participar dos encontros durante o horário ofertado seria possível acessar o material posteriormente, ampliando assim o número de acessos nas atividades formativas. O site contém seis abas:

1. Direcionadores gerais: com orientações de como desenvolver a atividade acadêmica presencial no ambiente virtual;

2. Capacitações gravadas: local onde estão disponíveis as gravações das capacitações pedagógicas e tecnológicas, para os professores que não conseguiram participar ou procuram assistir novamente;

3. Tutorial dos recursos Moodle: com vídeos para a adaptação das aulas.

4. Tutorial sobre o TEAMS;

5. Tutoriais para a produção de conteúdo, com PowerPoint com possibilidades de produção de material;

6. Suporte tecnológico, disponibilizando todos os canais de atendimento.

Na sequência, apresentamos a descrição das ações re77alizadas nas primeiras semanas. Nas duas primeiras semanas da migração, foi organizado um plantão pedagógico com professores de todas as Escolas e formação docente, para dar apoio presencial e por telefone para os docentes que sentissem necessidade. Destaca-se, nestes primeiros dias, o alto índice de procura nos atendimentos da TE, especialmente em função da plataforma Moodle. Muitos professores o utilizavam apenas como repositório de materiais, muitos não o utilizavam. Nestes dias, foram realizadas três formações online com os seguintes temas: principais recursos do Moodle - aspectos tecnológicos; planejamento de atividades a distância - aspectos pedagógicos; e webconferência tecnológica para exploração de recurso TEAMS para aulas síncronas. Essas formações tecnológicas e pedagógicas tinham como objetivo orientar sobre a constituição das aulas presenciais no ambiente virtual. Nessas três primeiras capacitações não foram registrados o número de professores participantes.

Na segunda semana, foram realizadas formações diárias das 14h às 16h e gravadas para que todos os professores pudessem assistir. Cada dia, os encontros abordavam tópicos diferentes: "orientações gerais e dicas para as aulas"; "produção da interatividade dos materiais pedagógicos"; "atividades colaborativas em grupo"; "trabalhos em grupo; avaliação e instrumentos de avaliação" (Quadro 1). Essas pautas foram sendo escolhidas a partir das demandas que surgiam dos professores.

Quadro 1- Descrição dos temas das formações da segunda semana e número de professores participantes

\begin{tabular}{|c|c|c|}
\hline & Tema do Encontro & $\mathbf{N}^{\circ}$ de participantes \\
\hline 1 & Orientações gerais e dicas para aulas no ambiente virtual & 45 \\
\hline 2 & Produção dos materiais pedagógicos & 40 \\
\hline 3 & Atividades colaborativas no ambiente virtual & 37 \\
\hline 4 & Trabalhos em grupo no ambiente virtual & 28 \\
\hline 5 & Avaliação e instrumentos de avaliação & 25 \\
\hline Total & & $\mathbf{1 7 5}$ \\
\hline
\end{tabular}


Destacamos a importância de expandir o repertório tecnológico dos professores e instrumentá-los para um novo paradigma pedagógico, pois a docência no ambiente virtual vai além de uma questão técnica, como o uso de equipamentos tecnológicos, incluindo o desenvolvimento de competências para o exercício profissional crítico e competente para o domínio das novas tecnologias digitais (GARCIA et al., 2012).

Na terceira semana, também foram realizadas formações diárias e gravadas. Cada dia a formação abordava um tópico diferente, compondo os encontros com professores convidados de diferentes áreas. Em dois dias da semana o tema foi "aulas teórico-reflexivas em ambiente digital”, em outros dois dias "aulas práticas/aplicadas em ambiente digital”; no quinto dia "práticas avaliativas no ambiente digital”. Nesta semana, tivemos 181 professores participando das atividades. $\mathrm{O}$ foco nesse momento foi compartilhar experiências dos professores de diferentes níveis de ensino e diferentes áreas, para que os professores observem o que pode ser feito em sala de aula a partir das experiências dos pares.

Na quarta semana, a universidade publicou uma instrução normativa sobre as aulas presenciais no ambiente virtual. Com essa normativa, ficou estabelecido que todas as aulas deveriam ser uma ministradas com pelo menos 1h30min de aula síncrona, e que a ferramenta de webconferências passaria a ser o Microsoft TEAMS. Esse direcionamento auxiliou os alunos, que acabavam tendo aulas em formatos e plataformas muito distintas; e também os professores, que passaram a se organizar a partir das orientações. No mesmo dia da publicação da normativa, foi anunciada uma sequência de capacitações tecnológicas para o uso do TEAMS, que ocorreu diariamente, das $11 \mathrm{~h}$ às $12 \mathrm{~h} 30 \mathrm{~min}$. Como muitos professores ainda não conheciam esta ferramenta, durante a quarta semana um grande número de professores participaram dos encontros de formação, resultando em $50 \%$ do corpo docente capacitado.

Na quinta semana, foram realizadas quatro encontros de formação sobre a temática da avaliação. A proximidade com o primeiro ciclo avaliativo do semestre e a permanência das aulas no ambiente virtual mobilizaram os professores a refletir sobre este processo. Assim, a cada dia foi abordado um tópico diferente dentro do tema: “concepção de avaliação e criação de avaliações utilizando o Forms, criação de questionário no Moodle e suas possibilidades de aplicação”. Nesta semana, tivemos a participação de 330 professores.

Dentre as principais orientações trabalhadas com os professores nestas primeiras semanas, podemos citar: a) garantir a entrega de qualidade em sala de aula, que nesse momento se configura no ambiente virtual; b) observar as características da atividade acadêmica no presencial e redesenhar as atividades de modo que as competências sejam desenvolvidas no ambiente virtual; c) compreender a situação dos alunos da turma, tanto no sentido de acesso e cultura digital quanto de organização do tempo, planejando atividades que possam ser realizadas considerando o contexto do aluno; d) organizar momentos semanais de interação com os alunos, que podem variar pelo uso de recursos síncronos e assíncronos.

Com esse relato de experiência, nosso objetivo não é esgotar em detalhes todas as ações ocorridas, mas compartilhar o conjunto de iniciativas que constituíram o percurso de formação de professores desta universidade. Ao refletirmos sobre essa experiência, nos propomos a realizar uma pesquisa pedagógica formativa, que segundo Masschelein e Simons (2014, p. 61) "têm a ver, em primeiro lugar, com a mudança de uma condição de existência do pesquisador, isto é, são uma questão existencial. Em segundo lugar, [...] não é apenas a relação entre conhecimento e verdade que desempenha um papel básico, a relação entre ética e verdade também o faz”. Em outras palavras, escrevemos também para transformar o que já sabemos e com isso qualificar nossas próprias práticas pedagógicas, seja como professora, seja como formadoras de professores. Por fim, escrevemos porque temos um compromisso ético com nossos colegas professores e com a qualidade do ES entregue por nossa IES. 
Ethos de formação: certo modo de ser e de agir, resultado de processos pelos quais cada um aprende a ver a si mesmo, a refletir sobre suas próprias ações, a operar transformações sobre si mesmo, este processo amplia-se e cria uma cultura de pertencimento, uma "morada”, uma comunidade partilhada. (DAL'IGNA; FABRIS, 2015, p. 78).

Desde o início de nossa atuação na equipe de formação docente (NIAF), nosso objetivo era desenvolver uma política de formação continuada, em sintonia com os direcionadores estratégicos e os princípios do Plano de Desenvolvimento Institucional (PDI) da universidade. Entendemos que, neste semestre 2020/1, não foi possível desenvolver um programa de formação docente estruturado, pois a cada semana o cenário ia se delineado e novas ações precisavam ser planejadas. Ainda assim, desenvolvemos nossas práticas a partir de princípios formativos já consolidados e o resultado é um senso de pertencimento e um alto índice de engajamento dos professores.

Além disso, era necessário consolidar a relevância deste setor para a entrega da qualidade almejada, pois a formação dos estudantes passa pelo ofício da docência. Embora esta seja uma caminhada que ainda está sendo percorrida, entendemos que o processo de formação docente desenvolvido em decorrência da migração das aulas para o ambiente virtual contribuiu neste sentido. Mais do que esse reconhecimento, é satisfatório pensarmos na formação como uma possibilidade de (trans)formação no modo de ser professor(a), desenvolvendo as competências digitais necessárias para os desafios que se apresentam neste século XXI, fortemente acelerado pela pandemia.

Por essa razão, sinalizamos para a construção de um ethos de formação (DAL'IGNA; FABRIS, 2015), um modo de ser e de agir na constituição da docência universitária pode ser um diferencial para os sujeitos professores que integram nosso corpo docente. A migração das aulas presenciais para o ambiente virtual possibilitou um processo de reinvenção potente, porque as condições exigiram que este fosse um momento de intensa adaptabilidade. Um momento em que conhecimentos pedagógicos precisaram ser revisitados ou até mesmo conhecidos, mas que sobretudo favoreceu a produção de novas práticas pedagógicas.

Em relação a experiência de formação docente que relatamos, vale destacar alguns pontos:

a) Do ponto de vista estrutural, a importância das gravações e da comunicação sistemática com o universo de professores que compõem o corpo docente da universidade (via informe diário, mensagens SMS, disparos nos grupos de WhatsApp dos colegiados);

b) A necessidade de ação rápida e estratégica por parte da equipe articuladora da formação, especialmente após decisão de unificação da ferramenta de webconferência para as aulas síncronas;

c) A receptividade e o engajamento de boa parte do corpo docente, que não mediu esforços para se adequar às demandas da migração;

d) A importância da articulação entre a Formação Docente (NIAF), as Unidades Acadêmicas e a Tecnologia Educacional.

e) Por fim, a importância dos fundamentos que dão sustentação às ações de formação docente, tais como aprendizagem entre pares, compartilhamento de práticas, busca de representatividade das diferentes áreas de conhecimento. Foram essas bases que nos permitiram agir rapidamente e engajar um número significativo de professores.

Como desafios para a continuidade do trabalho, nosso intuito é alcançar mais professores nas ações de formação docente; monitorar resultados das capacitações realizadas (considerando o olhar dos professores, alunos e gesto- 
res); manter o registro sistemático das ações realizadas, bem como a reflexão sobre o que se faz; articular as ações de formação aos dados das avaliações de satisfação (Ciclo de avaliação - NIAF). Da nossa parte, enquanto professoras que exercem também a função de articuladoras e proponentes de espaços de formação continuada no ambiente universitário, cabe continuar refletindo sobre os efeitos deste momento tão intenso de mudança no cenário da educação.

Daniel (2020) destaca que as instituições de ensino presencial provavelmente irão retornar após a pandemia à essa modalidade com algum alívio, porém os arranjos e as práticas pedagógicas criados durante a crise do COVID-19 deixarão um rastro duradouro. Para o autor, todas as IES se beneficiarão dos mecanismos que implementaram para continuar suas missões de formação em tempos de crise, onde a expansão do aprendizado online no Ensino Superior tende a se acelerar ainda mais.

As aulas presenciais remotas demonstram a importância da presença do professor qualificado, que recebe capacitação e formação docente constante. A formação constante e os desafios transformam e qualificam as trocas entre os professores, possibilitando na prática aprender ensinando e aprender fazendo. Quando o isolamento passar, queremos que o sentido de pertencimento e de autoria docente continuem latentes, para que nunca mais possamos ser os mesmos. É nesse processo de reinvenção constante, de conduzir a si mesmo de outros modos, que o ethos de formação se fortalece.

\section{REFERÊNCIAS}

BAIRRAL, M. A.; SILVA, B. V. A. Rede social? Uma decisão política e tecnológica docência online em um ambiente virtual de aprendizagem ou em um grupo de uma. EM TEIA - Revista de Educação Matemática e Tecnológica Iberoamericana, v. 9, n. 2, 2018.

BIESTA, Gert. Para além da aprendizagem: educação democrática para um futuro humano. Tradução de Rosaura Eichenberg. Belo Horizonte: Autêntica, 2013.

BRASIL. Constituição da República Federativa do Brasil. Brasília,1988.

BRASIL. Lei n. 13.979, de 6 de fevereiro de 2020. Dispõe sobre as medidas para enfrentamento da emergência de saúde pública de importância internacional decorrente do coronavírus responsável pelo surto de 2019. Diário Oficial da República Federativa do Brasil, Brasília, DF, 7 fev. 2020.

CAVALCANTE, Bruna Luana de Lima; LIMA, Uirassú Tupinambá Silva. Relato de experiência de uma estudante de Enfermagem em um consultório especializado em tratamento de feridas. J Nurs Health, Pelotas (RS), v.1, n.2, p. 94-103, jan/jun 2012.

CUNHA, Maria Isabel. A docência como ação complexa. In: CUNHA, Maria Isabel (Org.). Trajetórias e lugares de formação da docência universitária: da perspectiva individual ao espaço institucional. Araraquara, SP: Junqueira \& Marin; Brasília, DF: CAPES; CNPq, 2010.

DAL'IGNA, Maria Cláudia; FABRIS, Elí Henn. Constituição de um ethos de formação no Pibid/Unisinos: processos de subjetivação na iniciação à docência. Educação Unisinos, v. 19, n. 1, p. 77-87, jan./abr. 2015.

DANIEL, S. J. Education and the COVID-19 pandemic. Prospects, 2020. https://doi.org/10.1007/s11125-02009464-3.

DANTAS, Tânia Regina. Formação de professores em EJA: uma experiência pioneira na Bahia. Revista da FAEEBA - Educação e Contemporaneidade. Salvador, v. 21, n. 37, p. 147-162, jan./jul. 2012. 
FABRIS, Elí T. Henn; DAL’IGNA, Maria Cláudia. Nenhuma escola está imune às ondas de violência e conservadorismo. IHU On-line, n. 516, ano XVII, p. 56-60, dez. 2017.

GARCIA, M. F. et al Novas competências docentes frente às tecnologias digitais interativas. Teoria $\boldsymbol{E}$ Prática Da Educação, v. 14, n. 1, p. 79-87, 2012.

HODGES, Charles et al. The Difference Between Emergency Remote Teaching and Online Learning. EDUCAUSE Review, Mar. 2020. Disponível em: https://er.educause.edu/articles/2020/3/the-differencebetween-emergency-remote-teaching-and-online-learning. Acesso em: 21 jul. 2020.

LÉVY, Pierre. Cibercultura. São Paulo: Ed. 34, 1999.

MARTINS, Ana Patricia Sá; KERSCH, Dorotea Frank. Identidades em (dis)curso: práticas de multiletramentos didáticos com futuros professores. Fólio - Revista de Letras, v. 12, n. 1, p. 141-167, 2020.

MASSCHELEIN, Jan; SIMONS, Maarten. A pedagogia, a democracia, a escola. Belo Horizonte: Autêntica, 2014. (Coleção Educação: Experiência e Sentido).

MENDES, Bárbara Maria Macêdo. Formação de Professores Reflexivos: limites, possibilidades e desafios. In: SOBRINHO, José Augusto de Carvalho Mendes. Formação e Prática Pedagógica: diferentes contextos de análises. Teresina: EDUFPI, 2007.

MOREIRA, José António M.; SCHLEMMER, Eliane. Por um novo conceito e paradigma de educação digital Onlife. Revista UFG, V.20, 63438, 2020.

NARODOWSKI, Mariano. Onze teses urgentes para a pedagogia do contra-isolamento. Blog do Pensar a Educação. Maio de 2020. Disponível em: https://pensaraeducacao.com.br/blogpensaraeducacao/onze-tesesurgentes-para-uma-pedagogia-do-contra-isolamento/. Acesso em: 05 jun. 2020.

NÓVOA, António. Formação de professores e trabalho pedagógico. Lisboa: Educa, 2002.

PIMENTA, Selma Garrido; ANASTASIOU, Léa das Graças Camargos. Docência no Ensino Superior. 5 ed. São Paulo: Cortez, 2014 (Coleção Docência em Formação).

PRIMON, Cátia S. F.; ARROIO, Agnaldo. O Conhecimento Pedagógico dos Docentes de Química do Ensino Superior. Química Nova, São Paulo, v. 39, n. 3, p. 376-382, 2016.

SANTOS, E.; WEBER, A. Educação e cibercultura: aprendizagem ubíqua no currículo da disciplina didática. Diálogo Educacional, Curitiba, v. 13, n. 38, p. 285-303, 2013.

SCHLEMMER, Eliane; MOREIRA, José A . Modalidade da Pós-Graduação Stricto Sensu em Discussão: dos modelos de EaD aos ecossistemas de inovação num contexto híbrido e multimodal. Educacao Unisinos (Online), v. 23, p. 689-708, 2019.

TOMAZINHO, Paulo. Ensino Remoto Emergencial: a oportunidade da escola criar, experimentar, inovar e se reinventar. Revista do SINEPE/RS, abril de 2020. Disponível em: https://www.sinepe-rs.org.br/noticias/ ensino-remoto-emergencial-a-oportunidade-da-escola-criar-experimentar-inovar-e-se-reinventar. Acesso em: 21 jul. 2020.

VIDAL, K. D. B.; NETO, I. R. Políticas educacionais orientadas à inovação. Revista on line de Política e Gestão Educacional, Araraquara, v.20, n.2, p. 257-270, maio/ago. 2016. 
VIEIRA, A. A formação de professores para o ensino de Administração baseado em competências: possibilidades e desafios. 2014. Tese (Doutorado em Administração de Organizações) - Faculdade de Economia, Administração e Contabilidade de Ribeirão Preto, Universidad de São Paulo, Ribeirão Preto, 2014.

ZABALZA, M. A. Competencias docentes del profesorado universitario: calidad e desarrollo profesional. Madrid: Narcea, S.A de Ediciones, 2011. 